\title{
A ROLE OF PHONON-ASSISTED TUNNELLING IN ELECTRICAL CONDUCTIVITY OF CARBON NANOTUBE NETWORKS *
}

\author{
P. Pipinys and A. Kiveris \\ Department of Physics, Vilnius Pedagogical University, Studentu 39, LT-08106 Vilnius, Lithuania \\ E-mail: akiveris@vpu.lt
}

Received 13 June 2007; revised 28 November 2007; accepted 22 February 2008

\begin{abstract}
High-field transport properties of single-wall carbon nanotubes (SWCNT) are analysed on the basis of phonon-assisted tunnelling ( $\mathrm{PhAT})$ model. This model enables one to explain not only the temperature-dependent current-voltage characteristics of SWCNT, but also the crossover from a semiconducting-like temperature dependence conductivity to a metallic-like one as temperature is increased.
\end{abstract}

Keywords: carbon nanotubes, electrical conduction, phonon-assisted tunnelling

PACS: 73.40.Gk, 73.63.-b, 73.50.Fq, 73.50.-h

\section{Introduction}

Since their discovery in 1991 [1] carbon nanotubes have attracted much attention of researchers due to their unique properties like high current density, chemical inertness, high mechanical strength, etc. Kaiser et al. [2] pointed out similarity between the resistivity versus temperature behaviour $\rho(T)$ observed in SWCNT and that of highly conducting polymers, in particular the change of the $\rho(T)$ dependence from metallic to nonmetallic as the temperature was decreased. In analogy to the conducting polymers, the authors of $[2,3]$ have described this resistivity behaviour by a model of metallic conduction in aligned nanotubes with hopping or tunnelling through small electrical barriers corresponding to defects of various types.

The non-metallic temperature dependence of $\rho(T)$ in SWCNT at low temperatures has been one of the interesting problems. The existing interpretations of this problem can be classified into two categories: the variable range hopping (VRH) [3-6] or the weak localization (WL), which emphasizes the role of the junctions as energy barriers between metallic regions [2,7-10]. According to the VRH mechanism, the dependence $\rho(T)$ is described by the formula

$$
\rho(T)=\rho_{0} \exp \left(\frac{T_{0}}{T}\right)^{1 /(n+1)}
$$

\footnotetext{
* The report presented at the 37th Lithuanian National Physics Conference, 11-13 June 2007, Vilnius, Lithuania.
}

where $n$ is the dimension of the system and $T_{0}$ is fitting parameter. The reports of different authors vary in their findings on the dimensionality of the VRH, ranging from one to three dimensions.

There are a number of publications where a Luttinger liquid (LL) model is used for explanation of temperature behaviour of electrical conductivity in SWCNT [11-15]. If the SWCNT behave as the LL and there is a tunnelling barrier between the electrode and the SWCNT, the current and conductance are described by power laws [11,15]:

$$
I=b V^{\beta} \quad \text { and } \quad G(T)=a T^{\alpha},
$$

where $a$ and $b$ are constants. The power-law exponents for a $\mathrm{LL}$ are related by $\beta=\alpha+1$.

Although a behaviour of current-voltage $(I-V)$ data or conductance on temperature in some cases can be described by the LL model, the discrepancy between predicted values of the power-law exponents from the theory and those derived from the experimental data are often observed. For instance, Bae et al. [12] for fitting their data measured on CNT mats with the power law have invoked an additional term with linear temperature dependence. Hunger et al. [14] have shown that the characteristic scaling exponent $\alpha$ of SWCNT bundles was spread between 0.1 and 0.9 , while the theoretically calculated value of $\alpha=0.24$ [14]. Such a behaviour is incomprehensible within the context of the Luttinger liquid. Evidence of inapplicability of LL 
model for explanation of temperature-dependent $I-V$ data for individual nanotubes exhibit the recent results presented by Skákalová et al. [15], because exponent $\beta$ evaluated from the $I-V$ curves was found to be equal to 3.3 and $\alpha=3.9$ (for a $\operatorname{LL} \alpha<1$ ).

Moreover, there are publications in which other mechanisms are invoked. The authors of [16,17] suggested the scattering of electrons by phonons at higher fields. A plenty of mechanisms used for explanation of the temperature dependence of current peculiarities in SWCNT networks implies that the conduction mechanism in these materials is not fully understood. Recently we have shown that the temperature-dependent conductivity of nanotubular polyaniline [18] and other polymers $[19,20]$ can be explained by a model based on a phonon-assisted tunnelling (PhAT), as a mechanism of free charge carriers generation. Since the PhAT theory predicts an absorption/emission of phonons in the process of carrier tunnelling, the variation of current/conductivity with temperature will be determined by the competition of the absorption and emission of phonons. If the absorption of phonons prevails over their emission, the current / conductivity should increase with temperature. At high enough temperature and electric field the emission of phonons may dominate in the process of tunnelling, causing the tunnelling rate decrease with temperature and, in the same way, the diminution of the current, i.e. the positive temperature coefficient of resistivity. Thus, the charge localization being the reason for temperature dependence of conductivity, the $\mathrm{PhAT}$ mechanism provides a more complete explanation both in the region of low temperatures, where the conductivity is semiconductor-like, and in the regions of higher temperature with the metallic temperature dependences of the conductivity.

The main purpose of this paper is to show that temperature dependence of electrical conductivity in semiconducting SWCNT, including the crossover to metallic-like temperature dependence, could be explained by the field-induced phonon-assisted tunnelling theories. In this paper, we focus on the data of the crossover from a non-metallic to metallic sign of conductivity at temperatures between $4 \mathrm{~K}$ and $200 \mathrm{~K}$ and show that the trend of conductivity with temperature is well accounted for by the PhAT model similar to that used for polymers [18-20].

\section{PhAT model and comparison with experimental data}

\subsection{Theory}

It is assumed that carriers in the CNT networks appear due to a phonon-assisted tunnelling of electrons from localized electronic states at nanotube-electrode interface. If electrons released from these centres dominate, the current through the crystal $I$ will be proportional to the electron release rate $W$ and density of the centres $N$, i.e. $I \propto N W$. For the calculation of $W$ with participation of phonons we operate with the PhAT constructed in the effective mass approximation. In [21], an equation for the tunnelling rate dependence on field and temperature, $W(E, T)$, has been derived:

$$
\begin{gathered}
W=\frac{e E}{8 m^{*} \varepsilon_{T}^{1 / 2}}\left[\left(1+\gamma^{2}\right)^{1 / 2}-\gamma\right]^{1 / 2}\left[1+\gamma^{2}\right]^{-1 / 4} \\
\times \exp \left\{-\frac{4}{3} \frac{\left(2 m^{*}\right)^{1 / 2}}{e E \hbar} \varepsilon_{T}^{3 / 2}\left[\left(1+\gamma^{2}\right)^{1 / 2}-\gamma\right]^{2}\right. \\
\left.\times\left[\left(1+\gamma^{2}\right)^{1 / 2}+\frac{\gamma}{2}\right]\right\}, \\
\gamma=\frac{\left(2 m^{*}\right)^{1 / 2} \Gamma^{2}}{8 e \hbar E \varepsilon_{T}^{1 / 2}} .
\end{gathered}
$$

Here $\Gamma=8 a(\hbar \omega)^{2}(2 n+1)$ is the absorption band width of the centre, $n=\left[\exp \left(\hbar \omega / k_{\mathrm{B}} T\right)-1\right]^{-1}, \hbar \omega$ is the phonon energy, $\varepsilon_{T}$ is the energy depth of the centre, $e$ is electron charge, and $a$ is the electron-phonon interaction constant $\left(a=\Gamma_{T=0}^{2} /\left[8(\hbar \omega)^{2}\right]\right.$, where $\Gamma_{T=0}$ is the absorption band width at $T=0 \mathrm{~K})$. Consequently, we will use this equation to explain the peculiarities of current and conductivity dependences on temperature.

\subsection{Current-voltage dependences}

Current dependences on applied voltage of carbon nanotube networks have been presented in several works $[10,15,22,23]$. The main peculiarities of these dependences are their nonlinearity at higher voltages and strong dependence on temperature $T$. Such a behaviour of $I-V$ data is explicable in the framework of phononassisted model.

The current-voltage dependences, measured at various temperatures for a rope of semiconducting SWCNT by Moriyama et al. [22] and fitted to the theoretical $W(E, T)$ dependences using equation (3), are shown in Fig. 1(a,b). The calculation was performed using the value of $0.2 m_{\mathrm{e}}$ for effective mass [24]. In the higher temperature region, the phonon energy of $6 \mathrm{meV}$ was 

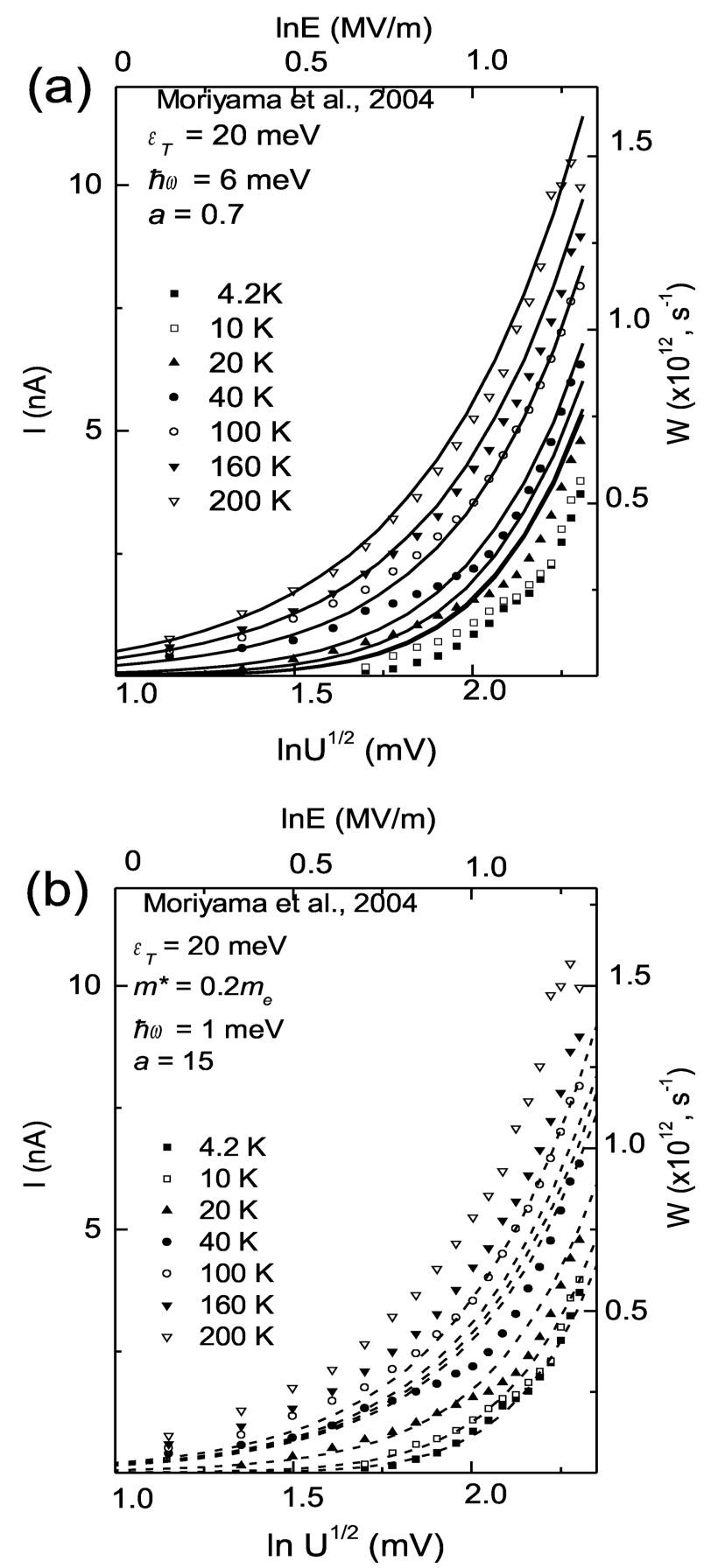

Fig. 1. Current-voltage data at various temperatures reported by Moriyama et al. from Figure 3(a) in [22] (symbols) fitted to the theoretical $W(E, T)$ versus $\ln E$ dependences, computed using the following parameters: (a) $\varepsilon_{T}=20 \mathrm{meV}, m^{*}=0.2 m_{\mathrm{e}}, a=0.7$, $\hbar \omega=6 \mathrm{meV}$ (solid lines) and (b) $a=15, \hbar \omega=6 \mathrm{meV}$ (dashed lines).

used for calculation (Fig. 1(a)) and the lower temperature data were fitted to theoretical curves computed using the value of $1 \mathrm{meV}$ for phonon energy. The electron-phonon coupling constant $a$ was chosen so that the best fit of the experimental data with the calculated dependences should be achieved, assuming that the field strength at the junction is proportional to the square root of the applied voltage, i.e. the tunnelling occurs in the high field region of the Schottky barrier. The centre depth (activation energy) $\varepsilon_{T}$ was estimated from the plot of $\ln I$ versus $1 / T$ at a $20 \mathrm{mV}$ sourcedrain voltage $V_{\mathrm{sd}}$, because only at a low voltage the slope of $\ln I(1 / T)$ curve allows one to determine the activation energy (data for plotting was obtained from Fig. 3(a) in [22]). As seen in Fig. 1(a), there is a good agreement of the experimental data with the calculated curves in the temperature range from 200 to $40 \mathrm{~K}$ only, because at lower temperatures the tunnelling rate is almost independent on temperature. The reason of this, in our mind, is that at temperatures lower than $40 \mathrm{~K}$ the phonons of $6 \mathrm{meV}$ energy are mostly "frozen" and the phonons of a lower energy could take part in the process of tunnelling. We note that there exists a grand variety of SWCNT vibration modes in the energy range from about 1 to $200 \mathrm{meV}[24,25]$ and the phonons of various energy may take part in tunnelling process. However, at low temperatures the population of high energy phonons is negligible and the low energy modes must be dominating. Indeed, the $W(E, T)$ dependences computed for the phonon energy of $1 \mathrm{meV}$ cover the experimental curves measured at low temperatures (see Fig. 1(b)).

A similar pattern is seen in the $I-V$ characteristics of aligned SWCNT measured by Lee et al. [23] in a temperature range from 10 to $300 \mathrm{~K}$. At room temperature $(300 \mathrm{~K})$, the $I-V$ curves were linear. Depending on the sample, the $I-V$ curves became nonlinear for $T<$ $100 \mathrm{~K}$. The authors [23] assigned the linear $I-V$ characteristics to metallic conduction, however, the nonlinear behaviour was not explained. The fit of these data with the computed $W(E, T)$ dependences using equation (3) for the phonon energy of $12 \mathrm{meV}$, as can be seen from Fig. 2 (dashed lines), shows a good agreement in the temperature range from 300 to $50 \mathrm{~K}$. But the curve at $10 \mathrm{~K}$ is outside of the theoretical curve computed for the same temperature, while the theoretical $W(E, T)$ curves computed for the phonon energy of $6 \mathrm{meV}$ (solid lines) cover the data measured at 10 and $50 \mathrm{~K}$ quite well. One can conclude that at low temperatures the phonons of lower energy dominate in the process of tunnelling.

\subsection{Current dependence on temperature}

Temperature dependence of conductivity $\sigma(T)$ is widely used for proving the VRH mechanism and its dimension according to equation (1). In the present section we will show that in many cases the temperature 


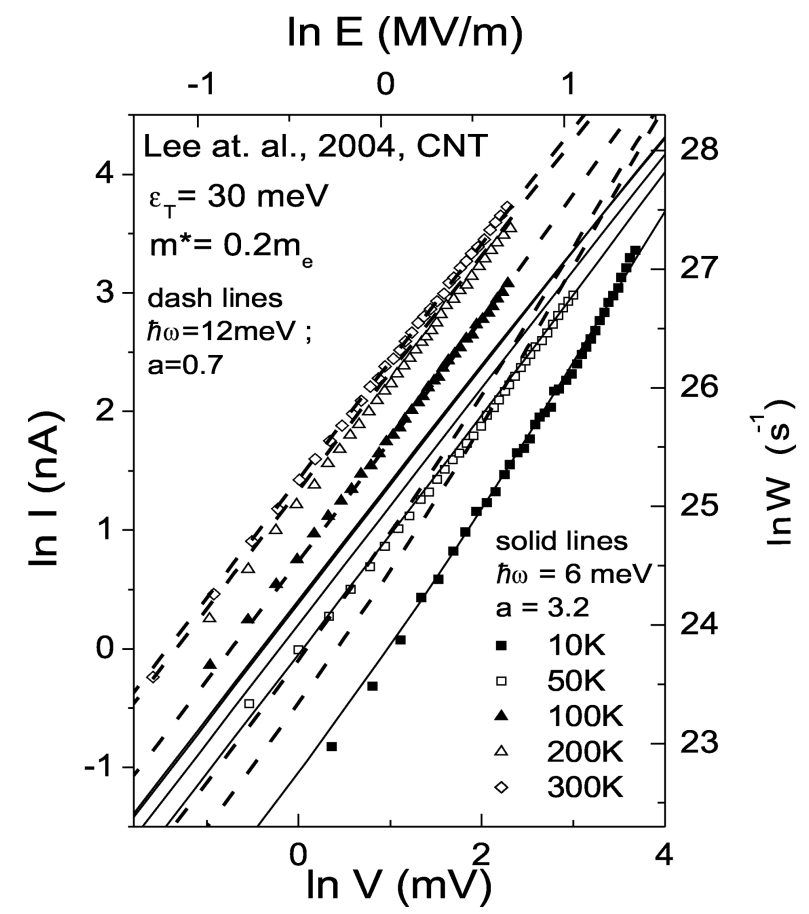

Fig. 2. Temperature-dependent $I-V$ characteristics of suspended SWCNT measured by Lee et al. from Figure 4(a) in [23] (symbols), fitted to $\ln W(E)$ versus $\ln E$ dependences computed for the same temperatures as experimental data and using parameters $\varepsilon_{T}=$ $30 \mathrm{meV}, m^{*}=0.2 m_{\mathrm{e}}, a=3.2, \hbar \omega=6 \mathrm{meV}$ (solid lines) and $a=$ $0.7, \hbar \omega=12 \mathrm{meV}$ (dashed lines).

dependence of the conductivity can be described on the basis of PhAT model. Figure 3 shows the temperature dependence of the current for a rope of SWCNT reproduced from [22]. According to authors of [22], such a behaviour of the current dependence on temperature suggests that the thermal emission current is dominant in the higher temperature range, while the temperatureindependent tunnelling current is dominant in the lower temperature range (see inset in Fig. 3). As can be seen in Fig. 3 (dashed line), the tunnelling rate $W(E, T)$ dependence on $1 / T$ computed for phonon energies of 6 and $1 \mathrm{meV}$ describes well the current in all range of temperatures.

We want to emphasize that this model enables one to describe the crossover of temperature-dependent conductivity from semiconducting-like to metallic-like, as temperature is increased $[9,12,26]$. To confirm this assertion we will compare the experimental data of resistivity versus temperature measured by Gaál et al. [26] on purified thick films of the single-wall carbon nanotubes. The "as made" sample had metal-like temperature dependence down to about $150 \mathrm{~K}\left(T_{\mathrm{C}}\right)$, with further resistance increase at lower temperatures. A heat treatment increases the room-temperature resistivity and pushes the temperature of crossover $T_{\mathrm{C}}$ higher,

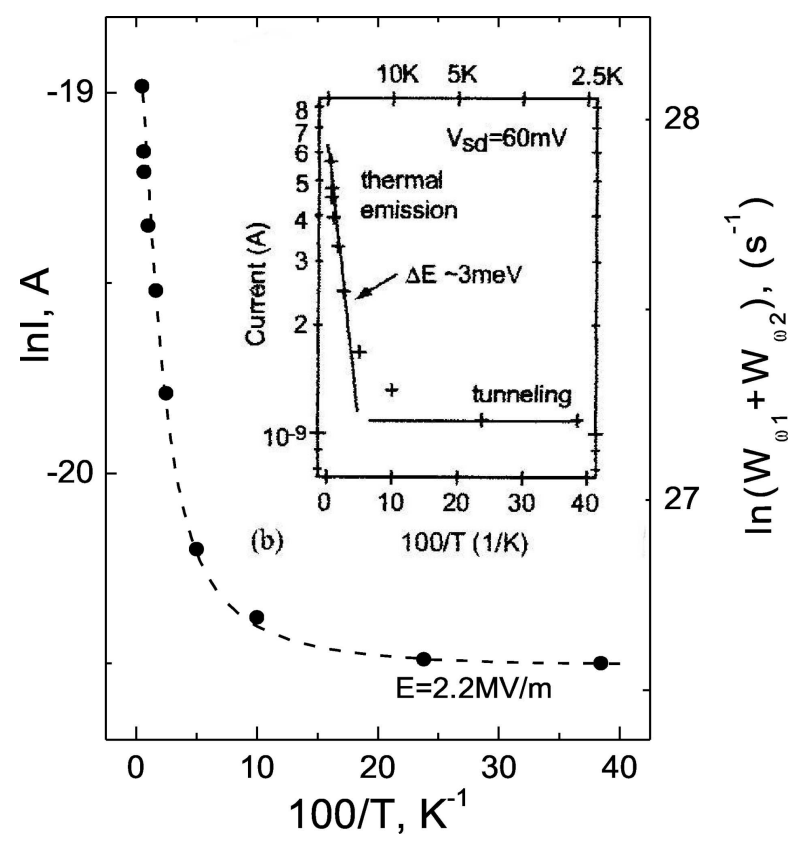

Fig. 3. ln-scale plot of the current as a function of inverse temperature reported by Moriyama et al. from Figure 3(b) in [22] (points) fitted to theoretical $\ln \left(W_{\omega 1}+W_{\omega 2}\right)$ versus $1 / T$ dependences, computed for field strenght of $2.2 \mathrm{MV} / \mathrm{m}$. The other parameters are the same as in Fig. 1. The inset shows the fit of the same data with thermal emission and tunnelling theories performed by authors of [22].

to about $350 \mathrm{~K}$. The fit of $1 / \rho$ extracted from Fig. 1 in [26] with theoretical dependence of $W(T)$ computed for barrier height of $34 \mathrm{meV}$ for the "as made" sample and $60 \mathrm{meV}$ for the heat treated one is shown in Fig. 4. It can be seen that $W(T)$ curves computed for the given field strength and the electron-phonon coupling constant fit well with the measured data. Thus, the decrease of conductivity at $T>T_{\mathrm{C}}$ could be attributed to a decrease of the electron tunnelling rate at temperatures above $T_{\mathrm{C}}$.

We want to note that Rogers and Kaiser [27] have described $\rho$ versus $T$ by the formula

$$
\rho=Q \exp \left(-\frac{T_{m}}{T}\right)+B \exp \left(\frac{T_{t}}{T_{s}+T}\right) .
$$

Here $Q$ and $B$ are coefficients, the first term expresses quasi-1D metallic conduction with $T_{m}$ indicating the energy required to backscattering of carriers, and the second term arises from fluctuation-assisted tunnelling through barriers, with $T_{t}$ corresponding approximately to the energy of the barrier and $T_{s}$ depending on the barrier parameters. The energy of the barriers deduced from fitting varied from 4 to less than $1 \mathrm{meV}$ for different samples. Thus the fit of the experimental data with Eq. (4) was performed involving a lot of parameters $\left(Q, B, T_{m}, T_{t}, T_{s}\right)$, the physical essence of which is mostly unclear, while the PhAT model appeals only 


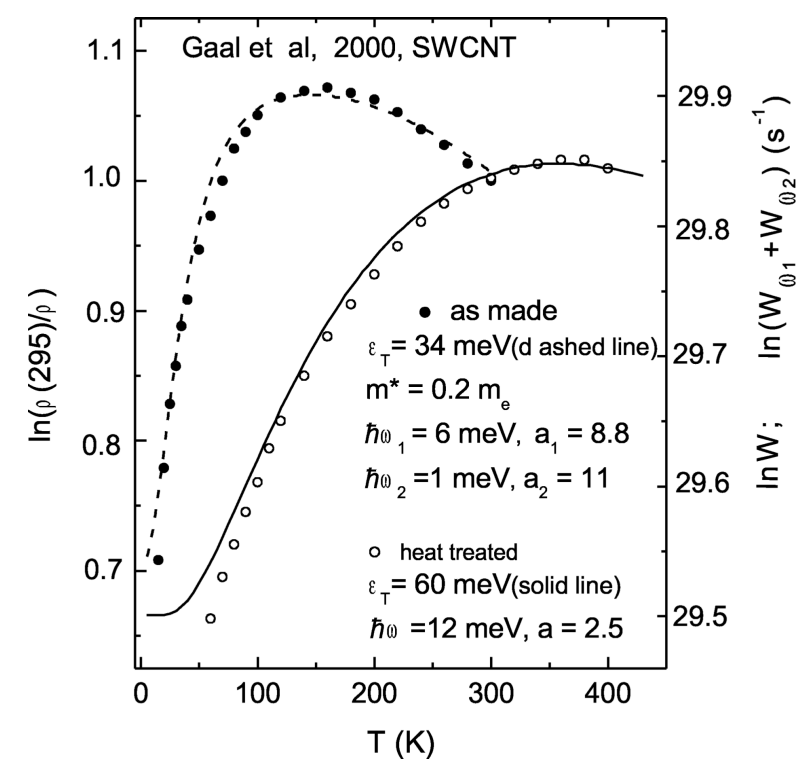

Fig. 4. Temperature dependences of the conductivity extracted from Gaál et al. from Figure 1 in [26], for "as made" (filled circles) and treated in vacuum at $1200{ }^{\circ} \mathrm{C} \mathrm{SWCNT}$ ropes (open circles), fitted to temperature dependences $\ln \left(W_{\omega 1}+W_{\omega 2}\right)(T)$, computed for $E=$ 6.4 MV/m (dashed line) and $E=14 \mathrm{MV} / \mathrm{m}$ (solid line).

to specific constants of the material, i.e. the effective mass, phonon energy, as well as the strength of the electron-phonon interaction.

\section{Summary and conclusions}

In summary, we have shown that the experimental results on the temperature-dependent conduction of SWCNT networks can be explained by the model based on PhAT initiated by electric field, as a free carrier generation process. The obtained agreement between the theoretical and experimental results, in our mind, is not accidental but is due to the fact that the proposed model includes ultimate pictures of charge transport in SWCNT networks. The reason of this assertion is that the number of experimental dependences, i. e. $I-V$ curves measured at different temperatures and conductivity dependence on temperature measured in a wide temperature range, is much greater than the number of fitted parameters. For the calculation of temperature and field-dependent tunnelling rate $W(T, E)$, six parameters were used: $T, \varepsilon_{T}, m^{*}, E, \hbar \omega$, and the electron-phonon interaction constant $a$. The values of 3 parameters $\left(T, \varepsilon_{T}, m^{*}\right)$ are known: $T$ and $\varepsilon_{T}$ from experiments, and the value of $m^{*}$ is published in literature. The other parameters that can be varied in a restricted range are $E$ and $\hbar \omega$. At low temperatures the modes of low energy phonons $(1 \mathrm{meV})$ were found to be appropriate. At higher temperature the phonons of higher energy ( 6 and $12 \mathrm{meV}$ ) from the discrete spectrum of phonons are proper for fitting the theory and experimental results. The most flexible parameter which was chosen from the best fitting is $a$, the value of which was found to be dependent both on barrier height and the value of phonon energy.

An advantage of the proposed model over the often used VRH model is the possibility to describe the behaviour of $I-V$ data measured at both high and low temperatures with the same set of parameters characterizing the material.

On the basis of the proposed model, the phenomenon of the crossover from non-metallic to metallic behaviour of the conductivity is also explained. The decrease of conductivity in the framework of this model occurs at $T>T_{\mathrm{C}}$, when phonon emission in the process of tunnelling dominates over phonon absorption. This effect is well described also by the equation (3), employing the same set of parameters as those used for fitting of other experimental results.

\section{References}

[1] S. Iijima, Helical microtubules of graphits carbon, Nature 354, 56-58 (1991).

[2] A.B. Kaiser, G. Düsberg, and S. Roth, Heterogeneous model for conduction in carbon nanotubes, Phys. Rev. B 57, 1418-1421 (1998).

[3] G.T. Kim, E.S. Choi, D.C. Kim, D.S. Suh, Y.W. Park, K. Liu, G. Düsberg, and S. Roth, Magnetoresistance of an entangled single-wall carbon-nanotube network, Phys. Rev. B 58, 16064-16069 (1998).

[4] Y. Yosida and I. Oguro, Variable range hopping conduction in bulk samples composed of single-walled carbon nanotubes, J. Appl. Phys. 86, 999-1003 (1999).

[5] W.Y. Jang, N.N. Kulkarni, C.K. Shih, and Z. Yao, Electrical characterization of individual carbon nanotubes grown in nanoporous anodic alumina templates, Appl. Phys. Lett. 84, 1177-1179 (2004).

[6] N.E. Mora-Huertas, P. Murugaraj, and D.E. Mainwaring, Temperature-dependent transport properties in the semiconducting regime of nanoparticle carbonpolyimide composite films, Physica E 24, 119-123 (2004).

[7] G. Baumgartner, M. Carrard, L. Zuppiroli, W. Bacsa, W.A. de Heer, and L. Forró, Hall effect and magnetoresistance of carbon nanotube films, Phys. Rev. B 55, 6704-6707 (1997).

[8] M. Baxendale, V.Z. Mordkovich, and S. Yoshimura, Magnetotransport in bundles of intercalated carbon nanotubes, Phys. Rev. B 56, 2161-2165 (1997).

[9] M.S. Fuhrer, M.L. Cohen, A. Zettl, and V. Crespi, Localization in single-walled carbon nanotubes, Solid 
State Commun. 109, 105-109 (1999).

[10] Ch.-K. Lee, J. Cho, J. Ihm, and K.-H. Ahn, Ballistic corrections to weak-localization conductance of carbon nanotubes, Phys. Rev. B 69, 205403-1-5 (2004).

[11] M. Bockrath, D.H. Cobden, J. Lu, A.G. Rinzler, R.E. Smalley, L. Balents, and P.L. McEuen, Luttingerliquid behaviour in carbon nanotubes, Nature 397, 598601 (1999).

[12] D.J. Bae, K.S. Kim, Y.S. Park, E.K. Suh, K.H. An, J.-M. Moon, S.Ch. Lim, S.H. Park, Y.H. Jeong, and Y.H. Lee, Transport phenomena in an anisotropically aligned single-wall carbon nanotube film, Phys. Rev. B 64, 233401-1-4 (2001).

[13] J.W. Park, J. Kim, and K.-H. Yoo, Electrical transport through crossed carbon nanotube junction, J. Appl. Phys. 93, 4191-4193 (2003).

[14] Th. Hunger, B. Lengeler, and J. Appenzeller, Transport in ropes of carbon nanotubes: Contact barriers and Luttinger liquid theory, Phys. Rev. B 69, 195406-1-4 (2004).

[15] V. Skakálová, A.B. Kaiser, Y.-S. Woo, and S. Roth, Electronic transport in carbon nanotubes: From individual nanotubes to thin and thick networks, Phys. Rev. B 74, 085403-1-10 (2006).

[16] Z. Yao, Ch.L. Kane, and C. Dekker, High-field electrical transport in single-wall carbon nanotubes, Phys. Rev. Lett. 84, 2941-2944 (2000).

[17] J. Vavro, M.C. Liaguno, B.C. Satishkumar, D.E. Luzzi, and J.E. Fischer, Electrical and thermal properties of $\mathrm{C}_{60}$-filled single-wall carbon nanotubes, Appl. Phys. Lett. 80, 1450-1452 (2002).

[18] P. Pipinys and A. Kiveris, Analysis of temperaturedependent conductivity of nanotubular polyaniline on the basis of phonon-assisted tunneling theory, Physica B 355, 352-356 (2005).

[19] A. Kiveris and P. Pipinys, Nonlinear $I-V$ character- istics in polyaniline due to phonon-assisted tunneling, Lithuanian J. Phys. 45, 133-137 (2005).

[20] P. Pipinys and A. Kiveris, Phonon-assisted tunnelling as a process determining current dependence on field and temperature in MEH-PPV diodes, J. Phys. Cond. Matter 17, 4147-4155 (2005).

[21] A. Kiveris, Š. Kudžmauskas, and P. Pipinys, Release of electrons from traps by an electric field with phonon participation, Phys. Status Solidi A 37, 321327 (1976).

[22] S. Moriyama, K. Toratani, D. Tsuya, M. Suzuki, Y. Aoyagi, and K. Ishibashi, Electrical transport in semiconducting carbon nanotubes, Physica E 24, 4649 (2004).

[23] S.W. Lee, D.S. Lee, H.Y. Yu, E.E.B. Campbell, and Y.W. Park, Production of individual suspended singlewalled carbon nanotubes using the ac electrophoresis technique, Appl. Phys. A 78, 283-286 (2004).

[24] V.N. Popov, L. Henrard, and P. Lambin, Electronphonon and electron-photon interactions and resonant Raman scattering from the radial-breathing mode of single-walled carbon nanotubes, Phys. Rev. B 72, 035436-1-10 (2005).

[25] S. Rols, Z. Benes, E. Anglaret, J.L. Sauvajol, P. Papanek, J.E. Fischer, G. Coddens, H. Schober, and A.J. Dianoux, Phonon density of states of single-wall carbon nanotubes, Phys. Rev. Lett. 85, 5222-5225 (2000).

[26] R. Gaál, J.-P. Salvetat, and L. Forró, Pressure dependence of the resistivity of single-wall carbon nanotube ropes, Phys. Rev. B 61, 7320-7323 (2000).

[27] S.A. Rogers and A.B. Kaiser, Thermopower and resistivity of carbon nanotube networks and organic conducting polymers, Current Appl. Phys. 4, 407-410 (2004).

\title{
TUNELINIŲ ŠUOLIŲ, STIMULIUOTŲ GARDELĖS FONONAIS, VAIDMUO ANGLIES NANOVAMZDELIŲ TINKLO ELEKTRINIAME LAIDUME
}

\author{
P. Pipinys, A. Kiveris \\ Vilniaus pedagoginis universitetas, Vilnius, Lietuva
}

\author{
Santrauka \\ Pateikiamas îvairių autorių tirtų anglies nanovamzdelių laidumo \\ rezultatų, gautų matuojant laidumo priklausomybes nuo temperatū- \\ ros ir elektrinio lauko stiprio, palyginimas su teorinemis krūvininku \\ tunelinių šuolių, dalyvaujant fononams, tikimybių priklausomybè- \\ mis nuo temperatūros ir elektrinio lauko stiprio. \\ Eksperimento ir teorinių skaičiavimo rezultatu palyginimas lei- \\ džia teigti, kad laidumo priklausomybes nuo lauko ir temperatū- \\ ros nagrinėjamuose dariniuose lemia laisvųjų krūvininkų tunelinè
}

generacija, kurios spartai didelę itaką turi gardelès vibroninè energija - fononai.

Pateiktasis modelis taip pat paaiškina, kodèl esant aukštesnei temperatūrai stebimas anglies nanovamzdelių elektrinio laidumo virsmas iš puslaidininkinio į metalinị, t. y. neigiamas savitosios varžos temperatūrinis koeficientas virsta teigiamu. Tai įvyksta dèl to, kad pakankamai stipriame lauke ir esant aukštesnei temperatūrai tunelini procesą lydi fononų emisija. 